\title{
Lesión de anatomía: Diamela Eltit o la autora sobre-expuesta en la escritura como crítica de lo Real
}

\section{Anatomy Lesion: Diamela Eltit or the Author Overexposed in Writing as a Critic of the Real}

\begin{abstract}
Resumen
El presente ensayo se concentra en dos libros inclasificables de la narradora chilena Diamela Eltit: El Padre Mío (1989) y El infarto del alma (1994). A partir de la sobre-exposición de la autora que allí se manifiesta en primera persona como volcada hacia el afuera ineludible de un encuentro con la diferencia, encarnada en la locura y el desamparo de los cuerpos del vagabundaje y el aislamiento psiquiátrico, respectivamente, así como de la responsabilidad que emerge como posición de discurso ante el acto problemático de darle forma a la materialidad de su presencia recuperada, recorro las maneras en que se perfila en ellos la otra escritura de una crítica de lo Real. Anudados en torno al estremecimiento subjetivo de quien se dispone a dar cuenta del "otro" en la escritura, en ambos textos atípicos dentro de la productividad teórico-ficcional de la escritora, y atópicos en el marco de lo que podría pensarse como un trabajo de no-ficción, la literatura y el arte se convierten en potentes espacios de lectura para el despliegue de una crítica cultural descolocada y políticamente comprometida en la visibilización de un Real inscrito en la Letra a través de los efectos que supone su inquietud.
\end{abstract}

Palabras claves 


\begin{abstract}
This essay focuses on two unclassifiable books by the Chilean storyteller Diamela Eltit: El Padre Mío (1989) and El infarto del alma (1994). From the overexposure of the author that manifests itself in the first person as overturned towards the unavoidable outside of an encounter with difference, embodied in the madness and the helplessness of the bodies of "vagabundage" and psychiatric isolation, respectively, as well as the responsibility that emerges as a position of discourse before the problematic act of shaping the materiality of its recovered presence, I go through the ways in which the other writing of a critique of the Real is outlined in them. Knotted around the subjective shiver of who is willing to account for the "other" in writing, in both atypical texts within the writer's fictional-theoretical productivity, and atopic within the framework of what could be thought of as a work of non-fiction, literature and art become powerful reading spaces for the deployment of cultural criticism dislocated and politically engaged in the visibility of a Real inscribed in the Letter through the effects of its concern.
\end{abstract}

Keywords

Diamela Eltit, El Padre Mío, El infarto del alma, overexposure of the autor, critique of the Real

La ficción de Eltit se construye precisamente sobre esa disyuntiva. Pensar la política, la catástrofe de lo real, desde la estética [...]. Como si el gesto que aproxima la letra al cuerpo mudo del loco pudiera de algún modo garantizar la encarnación ética de una política que si bien es pensada desde el arte y la experimentación extrema, no soslaya la problemática de su responsabilidad, de su inserción en el circuito de las interpretaciones sociales. Julio Ramos."Dispositivos del amor y la locura"

El derrumbamiento, el no-saber, se convierten en potencias en la escritura que los transmite. Georges Didi-Huberman. Supervivencia de las luciérnagas

En 1989, la escritora Diamela Eltit (Santiago de Chile, 1949), tantas veces invitada a participar en discusiones académicas sobre los problemas que organizan la productividad teórico-ficcional de su escritura, publica ese libro inclasificable que se desprende de su encuentro con un indigente esquizofrénico, y con su habla desestructurada, en un eriazo de la Comuna de Conchalí: El Padre Mío. Atípico entre las ficciones que, más o menos experimentales, componen la obra de esta narradora, y atópico respecto de lo que pudiera también pensarse como un trabajo de no-ficción, el texto irrumpe entre nosotros a la manera de un libro-objeto 
indiscutiblemente volcado hacia el exterior que le hace de litoral, y de cara al cual se propone como respuesta crítica - es decir, en crisis.

Desde el nombre que lo (a)firma -Diamela Eltit-, lo envuelve el ethos político-experimental de la llamada "Escena de Avanzada" de la cultura chilena (Richard, La insubordinación). Ese espacio de intervención estética y conceptual en el cual coincidieron artistas, escritores y críticos incómodos, hiperlúcidos y en gran medida contaminados entre sí, que desplegaron sus prácticas y discursos alternativos en contra del autoritarismo de la dictadura pinochetista; y continuaron demostrando su desacato durante los años posteriores de la reconfiguración democrática del país, frente a las "economías de signo liberal", y asimismo en oposición a las "poéticas representacionales de la izquierda institucional", según apunta Julio Ramos en el ensayo que dedica a ese otro libro extraño de la autora, El infarto del alma (Ramos 224), desde una perspectiva que en muchos sentidos acompaña y atraviesa mi reflexión. "Alrededor de la Escena de Avanzada", como afirma por otra parte Nelly Richard, "se desató una escritura crítica cuyo movimiento de combate - urgido y urgente- le exigía a la teoría deshacerse de la neutralidad expositiva de los metalenguajes científicos y liberarse, también, de los tecnicismos del saber académico" (Richard, La insubordinación 43). Dicho lo cual, continúa explicando la intensa coincidencia entre literatura, arte y teoría que este escenario cultural, en el cual se inscriben las búsquedas artístico-literarias de Eltit y las zonas de problematicidad social y cultural que traducen, abría como posibilidad de contestación y resistencia. Así, literatura, arte y teoría se anudaban allí en torno a la experiencia de crisis del entorno nacional y la búsqueda común de una manera de intervenir críticamente en ella:

El nuevo discurso -"que tuvo su expresión militante en un grupo de artistas plásticos y su adhesión a ciertos círculos de filósofos y literatos"acompañó, a partir de 1977, el trabajo de obras empeñadas en el desmontaje formal de las ideologías artísticas y literarias de la tradición cultural. Preocupado en recalcar la materialidad del significante (visual, 
textual) como plano y secuencia de crítica del significado, el discurso de la Escena de Avanzada fue explorando bordes de pensamiento que manifestaban un deseo de experimentación con el sentido más que de análisis e interpretación del sentido.

[...] Las teorizaciones heterodoxas del "discurso de la crisis" que practicó la Avanzada desacotaron las marcas de los saberes disciplinados para vagar fuera de las acumulaciones del conocimiento universitario protegidas por el culto de la especialización académica. (Richard, $L a$ insubordinación 43; énfasis de la autora)

Una nota introductoria en primera persona abre a la lectura el libro-objeto realizado en el acto de sobre-exposición de la autora hacia el afuera que hace causa en su deseo de escritura. Entre "etno-crítica" y poética, ella sirve de explicación al título enigmático que lo encabeza; y de marco, al habla indigerible del "Padre Mío" que se recoge más adelante entre sus páginas. Pero, además, establece el sesgo crítico a través del cual la autora se reconoce como interpelada por la contundencia de su "hallazgo" en medio de una exploración visual en torno a la "errancia" de los cuerpos que habitan en la periferia de la ciudad; y se dispone a la recuperación significante tanto de esos cuerpos y de su existencia desarraigada, como del habla en ruinas de la subjetividad en riesgo que la profiere. Ante el estremecimiento experimentado -nos dice-, y tras los cuatro años de silencio que lo continuaron, emerge "esta publicación". Una publicación que comienza por circunscribir, interrogar y elaborar las circunstancias que rodean la experiencia liminar de lo que ha sido una confrontación con lo Real de la indigencia y de la locura encarnadas en el cuerpo y el habla del "Padre Mío", así como los términos en que se asume la responsabilidad de su formalización difícil.

Se trata del registro de las tres hablas de ese hombre doblemente nómada porque indigente y porque esquizofrénico-, a quien la autora "llama" "el Padre Mío": ese hombre nombrado que fija el presente de su precaria existencia en/con el habla abigarrada del desvarío, que el libro-objeto significa y de la cual deja 
constancia. Es decir, el anónimo portador de una lengua en ruinas con el cual Eltit "se topa" en medio de una "inestable investigación en torno a la ciudad y los márgenes" (El padre mío 11). Investigación que cursaba, "sin un programa estructurado" (11), la exploración crítica de los espacios marginales del "vagabundaje" en Santiago de Chile, "persiguiendo delimitar y delinear una arista estética" (11), mediante la apertura de "un gran margen para la especulación" (11); "confiando en el quehacer narrativo que permitía tejer y unir creativamente distancias, liberando el flujo analógico y la carga estética incrustada en cuerpos, gestos, conductas y fragmentos de un modo de habitar" (11), "con la ventaja y desventaja de comparecer en esas zonas sin una mirada proveniente de la sociología o antropología” (11), y en compañía de la artista Lotty Rosenfeld, quien a su vez "iba documentando en video" (11) lo que no podía ser respaldado solo por la palabra:

Conocí al Padre Mío en 1983. Habitaba en un eriazo en la Comuna de Conchalí. Su modo de apropiación del espacio, hablaba de una ya larga instalación en el lugar; ropas colgadas en los arbustos, diarios antiguos, piedras de una fogata y un gran tarro lleno de agua demarcaban un centro que era recorrido una y otra vez por el hombre que llamo el Padre Mío. $[\ldots]$

Enjuto, rigurosamente limpio, su físico estragado acusaba el efecto de someterse a variadas e intensas condiciones climáticas. Vivía permanentemente a la intemperie.

Debo enfatizar su extraordinaria capacidad de sobrevivencia, dado que su mente estaba detenida en un punto único. Esa mente vaciada de realidad, dedicada a urdir la manera de descifrar su dolorosa y definitiva verdad. Aterrado en medio de un complot, el poder lo acechaba mortifero, convirtiéndolo en un sujeto que ya se había desprendido de todo, incluso de su nombre propio. El Padre Mío, en cada uno de los encuentros que 
CATEDRAL TomAdA: Revista de crítica literaria latinoamericana / Journal of Latin American Literary Criticism Lesión de anatomía: Diamela Eltit o la autora sobre-expuesta en la escritura como crítica de lo Real

sostuvimos, estaba en completo estado de delirio y, a pesar de eso, era capaz de autoabastecer sus necesidades vitales.

Este libro recoge tres encuentros; en 1983, 1984 y 1985 respectivamente, y en cada uno de ellos mi intervención se ha limitado a transcribir en forma fidedigna sus tres hablas grabadas en el eriazo de Conchalí.

Una interrogante me ha atravesado dilatando esta publicación por casi cuatro años: ¿Cómo situar este libro? Interrogante continua, fundamental, percibiendo, por otra parte, que la respuesta ya estaba contenida en el instante mismo de la grabación y, por ello, recuperación de esta habla, siguiendo la lógica de su salvataje en el deseo de su publicación, de esta publicación. (15-16; énfasis mío)

Más allá de una observación inicial acerca de la "corporalidad barroca temible en su exceso" (12), que Eltit identifica en la radical exterioridad de los cuerpos del vagabundaje urbano y en su materialidad pesada - "esculturas diseminadas en los bordes negando la interioridad arquitectónica", "ornamentos", "fachadas después de un cataclismo" (13)-, y a fin de "situar" un libro que no tiene otra justificación que "compartir" el "peso" de una experiencia estremecedora, y “diluir" la posterior "ausencia" (18) de ese "sujeto que ya se había desprendido de todo, incluso de su nombre propio" (15), la autora hubo de ubicarse -nos cuenta a continuación- "en un lugar diverso, un espacio de suplantación que no apela a revertir nada, a curar nada, como no sea instalar el efecto conmovedor de esta habla y la relación estética con sus palabras vaciadas de sentido" (16). Hubo de "actuar", pues, desde la "literatura" (16).

Y es desde la literatura, desde el monólogo de Beckett evocado, de donde surge un sentido posible para asimilar esa experiencia frente a la cual el texto crítico funciona como una pura potencia de contestación: la relación metafórica con el Chile de la dictadura, asida por la asociación que se establece entre el dolor del trauma y la implicación subjetiva manifiesta en su reconocimiento: "Es Chile, 
pensé.// Chile entero y a pedazos en la enfermedad de este hombre; jirones de diarios, fragmentos de exterminio, sílabas de muerte, pausas de mentira, frases comerciales, nombres de difuntos. Es una honda crisis del lenguaje, una infección en la memoria, una desarticulación de todas las ideologías. Es una pena, pensé” (17). A raíz de tal intervención de sentido, y por encima de las aporías implicadas en toda situación testimonial, el texto se propone como una instalación. Más allá cualquier voluntad enunciativa, resulta inminente "instalar el efecto conmovedor de esta habla" (16), a través de la cual la autora deja constancia, como cuerpo afectado y como firma, de "la situación vital del sujeto que habla" y de "la existencia rigurosamente real de los márgenes en la ciudad y de esta escena marginal" (16):

Desde dónde recoger esta habla era la pregunta que principalmente me problematizaba, especialmente, porque su decir toca múltiples límites abordables desde disciplinas formalizadas y ajenas para mí, como la siquiatría, por ejemplo.

Hube de ubicarme, otra vez, en un lugar diverso, un espacio de suplantación que no apela a revertir nada, a curar nada, como no sea instalar el efecto conmovedor de esta habla y la relación estética con sus palabras vaciadas de sentido, de cualquier lógica, salvo la angustia de la persecución silábica, el eco encadenatorio de las rimas, la situación vital del sujeto que habla, la existencia rigurosamente real de los márgenes en la ciudad y de esta escena marginal.

En suma, actuar desde la narrativa. Desde la literatura. $[\ldots]$

Evoqué la angustia del monólogo interior literario, esa prisa y profundidad por hablar la verdad "verdadera" del personaje escudado tras el simulacro formal de reproducir el pensamiento. Cuando escuché al Padre Mío, pensé, evoqué a Beckett, viajando iracundo por las palabras detrás de una madre recluida y sepultada en la página. 
CATEDRAL TomAdA: Revista de crítica literaria latinoamericana / Journal of Latin American Literary Criticism Lesión de anatomía: Diamela Eltit o la autora sobre-expuesta en la escritura como crítica de lo Real

Después de Beckett, me surgió otra imagen:

Es Chile, pensé.

Chile entero y a pedazos en la enfermedad de este hombre; jirones de diarios, fragmentos de exterminio, silabas de muerte, pausas de mentira, frases comerciales, nombres de difuntos. Es una honda crisis del lenguaje, una infección en la memoria, una desarticulación de todas las ideologías. Es una pena, pensé.

$[\ldots]$

El Padre Mío ya no habita más en ese sector. Retorné a esa zona en varias oportunidades. Pregunté por él en los alrededores: -Se fue, me contestaron.

La publicación de este libro me permite compartir su peso, dejar abiertas otras identificaciones. Me permite, especialmente, diluir su ausencia. (1718; énfasis mío)

En torno al reanudamiento de los cuerpos y del habla que hicieran a su experiencia de investigación y encuentro -su reanudamiento como texto en la escena crítica de un trabajo de recapitulación asociativa-, la autora que se expone en esta escritura inclasificable y descolocada, cifra la razón de ser de su autoría en la íntima necesidad de hacer manifiesto un vínculo (im)posible con el "otro" que falta. $\mathrm{O}$ en una urgencia, si se quiere, que es, al mismo tiempo, compromiso ético con la "verdad" de lo experimentado "en carne propia", y acción política de reconocimiento de esa "verdad verdadera" que la interpela; esa "verdad verdadera" con la cual se reconoce en deuda. Quizá por ello, a fin de cuentas, es ese vínculo el que le otorga un nombre y un sentido al libro-objeto extraño que, por otra parte, se instala entre nosotros como una doble llamada de atención: a imaginar la pesada materialidad de esas "esculturas" barrocas del vagabundaje, y a escuchar de entre ellas al "Chile" que se materializa en la lengua arruinada del "Padre Mío". Hombre enajenado y anónimo, el indigente no cesa de mencionar al "Padre Mío" en el discurso maniaco que repite sin orden ni concierto en una calle cualquiera del borde 
de la ciudad. Y es ese el nombre que Eltit rescata de su escucha para tramar el lazo que le permite ahora sobrellevar su ausencia. ¿No es, acaso, una "hija" del "Padre Mío" quien intenta de manera también precaria referir, identificar, explicar, puntuar lo vivido para poder compartirlo? ¿No ha visto, esa hija, arder en las llamas de un padecimiento extremo, al "Padre Mío" cuya habla resguarda del anonimato y la desaparición? "Es en eso, pues, en lo que la imagen arde" (Didi-Huberman 42), nos dice Didi-Huberman, en el ensayo que dedica a pensar esos lugares de la cultura en los cuales lo Real parece presentarse ante los ojos y oídos heridos del sujeto implicado en la experiencia de su encuentro como una interpelación que no puede ya ser desconocida:

Arde con lo real a lo que, en algún momento, se acercó (como cuando se dice, en los juegos de adivinanza, "te estás quemando" en lugar de "casi encuentras lo que está escondido"). Arde por el deseo que la anima, por la intencionalidad que la estructura, por la enunciación, e incluso por la urgencia que manifiesta (como cuando se dice "ardo por usted" o "ardo de impaciencia"). Arde por la destrucción, por el incendio que estuvo a punto de pulverizarla, del que escapó y del que, por consiguiente, es hoy capaz de ofrecer todavía el archivo y una imaginación posible. Arde por el resplandor, es decir, por la posibilidad abierta por su mismo ardor: verdad preciosa pero pasajera, debido a que está condenada a apagarse (como una vela que nos alumbra pero que, al arder, se destruye a sí misma). Arde por su intempestivo movimiento, incapaz como es de detenerse a medio camino (o de "quemar etapas"), capaz como es de bifurcarse constantemente, de tomar bruscamente otra dirección y partir (como cuando se dice de alguien que debió irse porque "está en llamas"). Arde por su audacia, cuando vuelve todo retroceso, toda retirada, imposible (como cuando se dice "quemar los puentes" o "quemar las naves"). Arde por el dolor del que proviene y que contagia a todo aquel que se toma la molestia de abrazarlo. Por último, la imagen arde por la memoria, es decir, 
que no deja de arder, incluso cuando ya no es más que ceniza: es una forma de expresar su vocación fundamental de sobrevivir. Y sin embargo... Pero, para saber todo esto, para sentirlo, es preciso atreverse, es preciso acercar el rostro a la ceniza. Y soplar suavemente para que la brasa, por debajo, vuelva a producir su calor, su resplandor, su peligro. Como si, de la imagen gris, se elevara una vos: “¿No ves que estoy en llamas?”. (DidiHuberman 42; énfasis del autor)

En este sentido, el "Padre Mío" - esa imagen que arde entre los cuerpos barrocos del vagabundaje urbano, como si desde ella se elevara la voz de una llamada- puede ser leído como el significante de la falta en el marco de una elaboración conceptual que gira en torno a ella como carencia y como ausencia. Por una parte, porque funciona como el sujeto vacío alrededor del cual se enhebra el delirio del habla que se recoge en el libro -“el Padre Mío” es el perseguidor, en el cual el delirio del indigente insiste. Por otra, porque termina encarnando la precariedad de la existencia desnuda que lo profiere -es el esquizofrénico, el loco que encuentra un nombre en el discurso del desvarío que lo significa. Pero, además, porque señala a la persona que había perdido hasta el nombre, y que un día desaparece del eriazo en la Comuna de Conchalí -el cuerpo sin rostro, sin hogar y sin cordura con el que la autora se topa en medio de una investigación más bien inorgánica por los márgenes de la ciudad. Y, finalmente, porque traduce la posición perturbada del sujeto al que interpela: Diamela Eltit, sujeto en falta de cuya crisis emerge, después de cuatro años de silencio, un texto "inclasificable" donde la crítica cultural se cruza con la sobre-exposición de la autora en la escritura que, inquietada, intenta dar cuenta de su confrontación con lo Real.

Lo demás, el texto incomprensible que queda registrado en la página como experiencia de encuentro y como habla, son las tres grabaciones del discurso del "Padre Mío" en el tiempo transcurrido de la experimentación y el contacto. Esto es: el discurso de ese "Padre Mío" que desvaría en un eriazo de la Comuna de Conchalí y que Eltit instala como documento de su acontecimiento "verdadero" en el espacio 
público del libro-objeto que en esos términos comparte, y que nosotros no podemos más que recibir. De hecho, si se tratara de un texto literario, tal cual el monólogo de Beckett evocado, las tres hablas delirantes del "Padre Mío" no serían ya ni legibles ni escribibles. Responderían, más bien, podríamos pensar con Barthes, a una suerte de "tercera entidad textual": "lo recibible". Es decir: "lo ilegible que engancha, el texto ardiente, producido continuamente fuera de toda verosimilitud y cuya función [...] sería la de impugnar la restricción mercantil de los escritos" (Barthes 129). "Este texto", continúa Barthes, "guiado, armado por un pensamiento de lo impublicable, suscitaría la respuesta siguiente: no puedo ni leer ni escribir lo que usted produce, pero lo recibo, como un fuego, una droga, una desorganización enigmática" (129).

No podríamos decir, sin embargo, que eso "recibible" que pulsa en las entrañas de El Padre Mío y que Eltit comparte en esta publicación es "literatura". Son diversas las aristas que, desde un tipo de "verdad" que poco tiene que ver con las certezas del saber orgánico que legitima la autoritas académica, una "verdad" de la cual casi nada se sabe, problematizan y perturban el espacio autónomo de la "creación literaria": es verdaderamente un delirio lo recogido por la autora y por la artista visual que la acompaña; y ese delirio no deja de ser un trozo de verdad desprendido del cuerpo que lo profiere en medio de un estado de evidente padecimiento. $\mathrm{O}$, cuando menos, es ese el pacto que funda la escritura no como ficción literaria sino como experiencia desgarradora. Por ello, en definitiva, esta escritura se hace cargo de un resto; y ese resto documenta, al mismo tiempo, la "verdadera verdad" de su hallazgo en un eriazo de la Comuna de Conchalí: la del desvarío de la persona en la que ese hallazgo (de la diferencia) encarna, y la de la perturbación que genera en la subjetividad descolocada de la crítica que escribe a partir de ella. En la intimidad de su experiencia, la autora registra; y en el acto crítico que la publicación de ese registro supone se establece, a la vez, tanto el venir a la presencia del "Padre Mío", como el devenir texto/elaboración de sentido de esa experiencia incorporada como acontecimiento a través de la palabra $-\mathrm{y}$ acción política, en consecuencia, de la autora que se sobre-expone en/a su instalación: 


\section{SU PRIMERA HABLA}

(Grabada en 1983)

Usted me lleva con el plan de eso. -¿Cómo no voy a saberlo yo?--. Si yo soy el hombre que va a dar las órdenes aquí yo. Voy a dar las órdenes en el país. Porque yo no tengo compromisos con ellos ni con el rey Jorge, que está últimamente dando las órdenes, que posee ese rango. El Padre Mío da las órdenes ilegales en el país. Hace muchos años que subsiste de ingresos bancarios ilegales, del dinero que le pertenece a la concesión del personal de la Administración. El es cómplice con el Padre Mío en estos asuntos. Yo les quiero hacer un servicio a ustedes por las ventas de sus derechos. Porque yo fui solicitado para ocupar esos cargos y esas garantías, no el Padre Mío ni el señor Colvin que es el señor Luengo, que es diputado y senador. A él le ofrecieron esos cargos y esas representaciones; por eso que a mí me planearon por asesinato y enfermo mental. Se pagó un dinero importante por lo mío. El canto hay que superarlo, él es Argentino Ledesma, yo soy el que lo superó a él como cantor. A mí me tienen planeado más de veinte años en esos asuntos [...]. (El Padre Mio 22-23)

Casi una década después, en 1994, aparece la primera edición de El infarto del alma, con textos de Diamela Eltit y fotografías de Paz Errázuriz. Entre las ficciones que la autora publica más o menos cercanamente a aquel texto inclasificable que es El Padre mío, siempre atravesadas por la conciencia teórica y crítica que las organiza, y esta segunda "rareza" textual-Lumpérica (1983), Por la Patria (1986), El cuarto mundo (1988), Vaca sagrada (1991), Los vigilantes (1994)-, El infarto del alma se inscribe también en el nosotros de la lectura como el documento que traduce, a través de la formalización heterológica de su factura, una manera distinta - del testimonio, por ejemplo, y/o del relato confesional- de registrar la "verdad" ineludible del estremecimiento producido por otro encuentro 
con lo Real de la diferencia y su dolorosa manera de existir como resto" . "Fotoensayo", al decir de Julio Ramos (223), los textos de Eltit y las fotografías de Errázuriz intercaladas que hacen a la singular composición de este segundo libroobjeto se desprenden de nuevo de una suerte de incursión en los espacios de la marginalidad subjetiva y urbana: del viaje que ambas autoras comparten a un manicomio estatal situado en el pueblo de Putaendo, a dos horas de Santiago de Chile. O, cuando menos, eso refiere el "Diario de viaje (Viernes 7 de agosto de 1992)" que, desde las primeras páginas del volumen, ancla el delirio de la escritura, al mismo tiempo asociativa y disociada, que se desencadena luego entre ellas, bajo la forma aún contenida de una precaria contextualización:

Días antes he visto las fotografías.

Ahora viajamos con Paz Errázuriz en dirección al hospital psiquiátrico del pueblo de Putaendo, un hospital construido en los años cuarenta para asistir a enfermos de tuberculosis y que, luego de la masificación de la vacuna preventiva, es convertido en manicomio recibiendo pacientes de los distintos centros psiquiátricos del país. Enfermos residuales, en su mayoría indigentes, algunos de ellos sin identificación civil, catalogados como N.N. Mientras viajamos, el paisaje se vuelve francamente cordillerano, la luz lo atraviesa todo cuando aparece el imponente edificio recortado contra la cadena de cerros. A dos horas de Santiago la construcción me parece demasiado urbana, como si un pedazo de ciudad

${ }^{1}$ Me refiero al término "Real" desde una perspectiva en la que re cruzan el psicoanálisis lacaniano (en contraposición a lo "Simbólico" y lo "Imaginario", para Lacan, lo "Real" es lo que no puede ser alucinado por el sujeto), y cierto uso al que recurre el postestructuralismo francés para pensar el desbordamiento de lo simbólico por la presencia material de eso que lo contesta desde la radicalidad de su diferencia. En un sentido cercano, Florencia Garramuño habla de los "restos de lo Real" para describir las maneras en que la literatura latinoamericana de las últimas décadas del siglo XX incorpora elementos residuales de ese "afuera" histórico y material del ámbito de las representaciones en sus propios procesos de exploración política y estética. El encuentro con lo "Real", en el caso de Diamela Eltit, traduce una experiencia de confrontación con la materialidad indiscutible del "otro": ese cuerpo distinto, cuya presencia excede a la representación, y de la cual el sujeto apenas puede dar cuenta a través de la angustia que le produce. 
se hubiera fugado - a la manera de una fuga psicótica- para formar de manera solitaria una escena sorprendente.

La reja, la caseta de control, después los jardines, más atrás el edificio. Cuando atravesamos la reja veo a los asilados. No me resultan inesperados sus cuerpos ni sus rostros (no me resultan inesperados pues ya dije que días antes he visto las fotografías), solo me desconcierta la alegría que los recorre cuando gritan: “Tía Paz”. “Llegó la tía Paz”. Una y otra vez como si ellos mismos no lo pudieran creer y más la besan y más la abrazan y a mí también me besan y me abrazan hombres y mujeres ante los cuales debo disimular la profunda conmoción que me provoca la precariedad de sus destinos. No sus rostros ni sus cuerpos, me refiero a nuestro común y diferido destino.

¿Qué sería describir con palabras la visualidad muda de esas figuras deformadas por los fármacos, sus difíciles manías corporales, el brillo ávido de esos ojos que nos miran, nos traspasan y dejan entrever unas pupilas cuyo horizonte está bifurcado? ¿De qué vale insistir en que sus cuerpos transportan tantas señales sociales que cojean, se tuercen, se van peligrosamente para un lado, mientras deambulan regocijados al lado de Paz Errázuriz, ahora su parienta?

La tía que les toma fotografías que prueban, aun frente a ellos mismos, que están vivos, que después de todo conservan un pedacito de ser, aunque habiten como enfermos crónicos en el hospital más legendario de Chile, el manicomio del pueblo de Putaendo, ahora llamado Philippe Pinel. Leo ese nombre escrito en el frontis del edificio. Estamos rodeadas de locos en un desfile que podría resultar cómico, pero, claro, es inexcusablemente dramático, es dramático de veras más allá de las risas, de los abrazos, de los besos, pese a que una mujer me tome por la cintura, ponga su boca en mi oído y me diga por primera vez: "Mamita". Ahora yo también formo parte de la familia; madre de locos. 
De esa manera entramos al edificio, abiertas a la profundidad de nuestra propia insanía, cercadas por los cuerpos materiales que me parecen cada vez más definitivos, incluyendo toda la notoria desviación de sus figuras. Cuando cruzamos la puerta, experimento un nuevo impacto: escucho algo parecido a un canto que se extiende y cruza todo el pabellón, una música ejecutada con el movimiento febril y continuo de la lengua que me hace evocar los sonidos de los bereberes, los nómades del desierto, de un desierto que no conozco, de un sonido que retengo de manera vaga desde quizás qué filme, desde no sé cuál olvidada grabación. Recuerdo la música del desierto impresionada por la potencia de la garganta que me conduce hasta la primera escalera, que me enfrenta al primer corredor del hospital, a la primera ventana, que me transporta directamente a la primera señal del encierro. (Eltit y Errázuriz, El infarto del alma s.p.; énfasis mío)

A pesar de la pregnancia de las imágenes que se van formulando alrededor de este primer contacto con el "hospital más legendario de Chile", y de la evidente afectación subjetiva que traslucen respecto de la conciencia que las anota, no son los "enfermos residuales, en su mayoría indigentes", ni es la "precariedad de sus destinos", ni "la visualidad muda de esas figuras deformadas por los fármacos, sus difíciles manías corporales, el brillo ávido de esos ojos que nos miran, nos traspasan y dejan entrever unas pupilas cuyo horizonte está bifurcado"... la razón última que anima esta experiencia de exploración y contacto hacia el interior de ese lugar inquietante que se anuncia como tal desde "una música ejecutada con el movimiento febril y continuo de la lengua que me hace evocar los sonidos de los berebere, los nómades del desierto, de un desierto que no conozco". No lo son, tampoco, el anonimato y el encierro psiquiátrico de esos cuerpos dramáticamente regocijados ante la visita de Paz Errázuriz, la "tía que les toma fotografías que prueban, aun frente a ellos mismos, que están vivos, que después de todo conservan un pedacito de ser". Ni es la constatación tajante, ante la voz que la nombra 
"Mamita", de que "Ahora yo también formo parte de la familia; madre de locos". De nuevo ella, la autora de este texto a través del cual nuevamente se expone; ella que en otra escena de exploración y contacto fuera la hija de un "Padre Mío" asimismo indigente y loco.

Hay más, aún, involucrado en la experiencia de este tránsito al cual las autoras se arriesgan, "abiertas a la profundidad de nuestra propia insania". Esta experiencia que se traducirá como contagio en la escritura que enloquece para poder hablar después de lo vivido. En principio, el viaje tiene un propósito previsto por la investigación visual de Paz Errázuriz, que Eltit se dispone a acompañar desde una escritura más poética que ficcional: registrar, identificar, reconocer y dejarse "tocar" por las formas del amor en el manicomio del pueblo de Putaendo; y asumir, en consecuencia, la conmoción que a partir de allí se diseminará - como un infarto del alma que la autora (a)firma como "propia" desde la primera persona sobreexpuesta en la escritura- en el texto de este nuevo experimento de una posición crítica descolocada:

Más adelante, de pasillo en pasillo, de escalón en escalón, en medio de los patios, saludo a la segunda, a la tercera, a la décima pareja. Hay tantos enamorados que ya pierdo la cuenta. "Él me da té y pan con mantequilla". "La cuido yo". Se alimentan, se cuidan. Se alimentan un poquito y se cuidan como pueden y a la manera radiográfica veo la gran metáfora que confirma a toda pareja; la vida entera anexada a otro por una taza de té y pan con mantequilla. Ellos están viviendo una extraordinaria historia de amor encerrados en el hospital; crónicos, indigentes, ladeados, cojos, mutilados, con la mirada fija, caminando por las dependencias con todos sus bultos a cuestas. Chilenos, olvidados de la mano de Dios, entregados a la calidad rígida del Estado. (Eltit y Errázuriz, El infarto del alma s.p.; énfasis mío) 
Son esos los locos que interesan a la lente de Paz Errázuriz: los locos enamorados al interior del encierro psiquiátrico. Esos locos heterogéneos que se encuentran, más allá de la experiencia aislada del delirio que los atraviesa, en una locura distinta: la del amor en el manicomio. Por supuesto, la escucha de la sujeto que da cuenta de ello en medio de su estremecimiento no puede no desviarse del amor, a la precariedad de los cuerpos; y de esa precariedad, a la absoluta indefensión de esos cuerpos precarios que se aman como locos más allá de la locura que padecen. Al final del viaje, sin embargo, se imponen el silencio y la confusión: ¿qué hacer con esta experiencia, qué quedará de ella? "Pensaré en el amor", afirma la autora afectada por la materialidad de lo que experimenta "en carne propia". Y, desdiciéndose, problematizada, tocada por el afecto, añade:

No pensaré en el amor, lo que me ocupará será ese amor que fluye, se dispara, se dispersa al interior del baldío hospital público. Recordaré que hace un año, cuando conversábamos en México, Paz Errázuriz me habló de su ya largo trabajo, me dijo que hacía retratos de los pacientes enamorados del hospital del pueblo de Putaendo. Sentiré que hace todo un año que las palabras dan vueltas por mi cabeza y, sin embargo, cuando emprenda el viaje de retorno iré silenciosa, vacía.

Volveré a la ciudad atrapada en el manicomio de mi propia mente y después caminaré mucho tiempo de un lado para otro, subiendo y bajando escaleras, tambaleando entre pasillos, atravesando patios, cargando a esos cuerpos en un pedazo de mi cerebro. Iré de un lado para otro llevando a esos cuerpos con la desdicha y con la fuerza de un alma en pena. (El infarto del alma s.p.; énfasis mío)

El resto del libro contiene los retazos de escritura que emergen, otra vez, como pura potencia de contestación: una respuesta que tiende a toparse con su propia imposibilidad de alcanzar una forma capaz de contener lo que ha sido vivido como una profunda desorganización subjetiva. No podemos más que "recibir", 
entonces, como si se tratara de un atípico y atópico texto literario, esa desorganización de la cual la escritura deja constancia: trozos de un poema sobre la falta que no consigue significarse sino como "hambre"; apuntes de una reflexión sobre la diferencia que se desvía en la deriva asociativa hacia la imagen de la madre y hacia el amor como una experiencia de disolución subjetiva; memorias de otros textos literarios que, en la historia cultural de Occidente, reunieron amor y enfermedad en algunas de las metáforas que desplegaron sus autores para imaginarse en el exceso... Y decir, con Barthes, otra vez: "no puedo ni leer ni escribir lo que usted produce, pero lo recibo, como un fuego, una droga, una desorganización enigmática” (Barthes 129).

Como si se tratara de la protagonista de alguna historia de amor contada por la excéntrica brasileña Clarice Lispector -ese último relato póstumo de la autora, por ejemplo, "La Bella y la Bestia o la herida demasiado grande" (1979), acerca de la mujer que no puede más que abandonarse a la profunda desorganización que le produce su encuentro con la herida purulenta de un mendigo, quien interrumpe la narcisista contemplación de su belleza con la demanda inesperada de una limosna en la puerta del hotel Copacabana Palace; y/o, incluso, su rara "novela", A Paixão segundo G.H. (1964), donde los trazos de un dibujo dejado en la pared por la empleada doméstica que se ha marchado del apartamento y el posterior encuentro con una cucaracha que se asoma desde lo profundo de un armario, detonan el delirio asociativo de ese proliferante monólogo interior que termina convirtiéndose en un viaje hacia el desierto de la propia interioridad devastada- el texto de Eltit se precipita, desencajado, sobre las páginas del libro-objeto que materialmente lo contiene. $\mathrm{Y}$ de esa precipitación $-\mathrm{y} / \mathrm{o}$ del desvarío que traduce- da cuenta el fragmento titulado "El infarto del alma": esa escritura enigmática y desorganizada que abre y cierra el libro y que se repite cuatro veces entre sus páginas a manera de interpelación al "Otro" ausente de una ausencia que finalmente se materializa como tal en la escritura; el "Otro" ausente de la demanda de amor que pulsa tras la ficción de su escucha (im)posible en la locura amorosa que la autora comparte con los locos que la nombraron "Madre": 


\section{EL INFARTO DEL ALMA}

Te escribo:

¿Has visto mi rostro en alguno de tus sueños?

¿Aparezco en tus sueños reprochándote por las abrumadoras faltas que contiene el pasado? ¿Sufres al despertar o te entregas a la invasora conciencia?

Ah, tú y yo habitamos en una tierra difusa, con grietas tan profundas que impiden el encuentro. A quién podría decirle que el ángel se niega a llevarme sobre sus espaldas y me desprecia y me abandona en las peores encrucijadas que presentan los caminos. No hay sombra más devastadora, más poderosa que la que proyecta el vuelo de un ángel. Sé que necesito una espada para abrirme camino ahora que la tierra acaba de espesarse. Podría confesar, en este mismo instante, que cuando te vi lejano quise que la intransigente tierra te cegara. Imaginé una muerte digna de tu altura, llegué a pensar que mi propia mano se haría vengativa. ¿Con qué derecho hubiste de torcer el curso de mi mano? Pero nada de eso permanece, hoy sólo espero que el ángel me lleve trepada por su espalda. Quiero que el ángel se curve por mi peso y sude y se maldiga por el abyecto trabajo de cargar mi humano cuerpo. (El infarto del alma s.p.; texto inicial)

\section{EL INFARTO DEL ALMA}

Escribo:

Nada deseo más que a mi propio deseo. Qué extraordinaria la conversión compasiva de Dios. Un animal exhausto se arrastra en celo hacia la profundidad de su madriguera. El último satélite intenta inútilmente medir el diámetro de expansión de la tierra. Mi amado trastabilla en la taberna clandestina sostenido por una muchacha robusta. Mi amado está muy pálido, muy tosco, demasiado ebrio, arrobado por el desafío que le presenta la cadera. Besaré mi propia boca fugazmente apenas se produzca 
la primera distracción en la noche. Besaré mi boca y untaré de saliva mi espectacular dedo índice. Tan costosa la vida, pareciera que únicamente el acto de morir fuera gratuito. Mi amado se emborracha y se emborracha en la taberna clandestina. Los banqueros se ríen ante la desesperación del préstamo. Mi amado nunca me regaló un vestido de seda. El satélite cae locamente a la tierra y quema la cabeza de su padre científico. Cuánto habremos de avergonzarnos por su espantoso fracaso. Deberé besarme, morderme la boca en cuanto se descuide la noche. Mi amado besa a una mujer opulenta [...] Vivo muy lejos, muy apartada de los inversionistas. El animal en celo agoniza de manera salvaje en el fondo del pozo. A mis amigos les fue negado el pan, se les escurre el agua de los labios. Mis amigos aunque no son puros experimentan siempre la pureza. Mi amado se va quedando y quedando en la taberna. ¡Ah, mi amado tan ebrio, tan cansado mi amado! (El infarto del alma s.p. texto final)

A un costado de la escritura, el resto silencioso que las fotografías de Paz Errázuriz registran se deja acompañar por la trama heterológica de retazos que se van sucediendo a lo largo de la lectura. Y cada imagen es un agujero de la serie que apuntala con su gestualidad muda la "verdad" que detona el propio desquiciamiento de las palabras; el devenir "resto" de la escritura - "lituratierra", diría Lacan, como esa en la que se convierte la escritura de Joyce, desparramada en la página sobre la cual se vierte en el acto de su incontinencia (Lacan 19 y ss.). "Después de todo, ¿qué se puede saber de la locura?”, inquiere Julio Ramos. “¿Cómo pensarla, si a ciencia cierta sabemos que ella, la locura, encarna el extravío, la errancia misma del pensamiento? ¿Qué discurso será capaz de hacerse cargo, de dar cuenta fiel de la cosa irreductible que en la locura excede la posibilidad misma del discurso, quebrando la lógica de su sentido, atravesando los límites de la comunicabilidad con el tajante recorrido de su voz rota y sus murmullos?” (Ramos 219). 


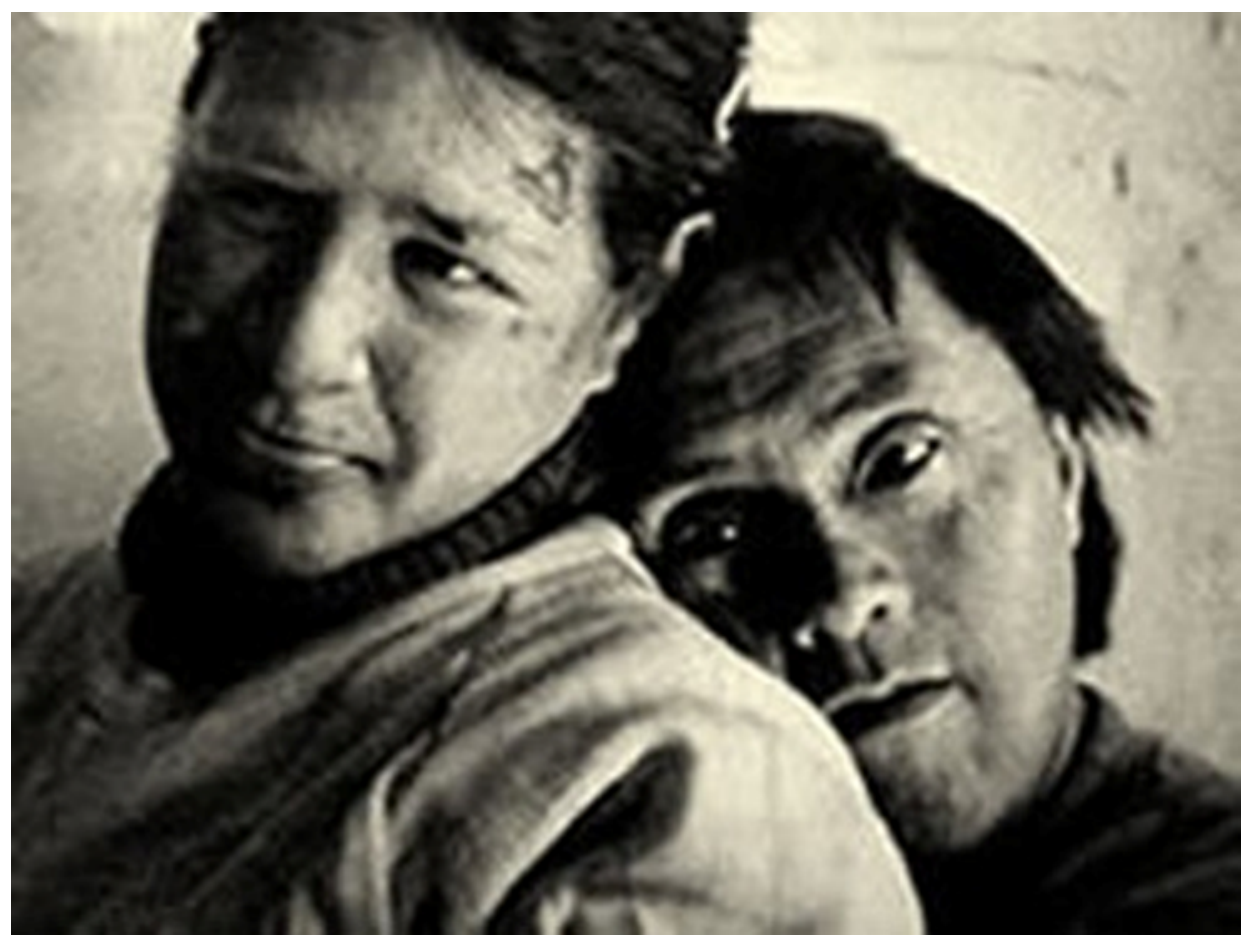

Figura 1. El infarto del alma s.p.

Desmontar y remontar hasta la intensidad Robert Bresson. Notes sur le cinématographe (Georges Didi-Huberman. Remontajes del tiempo padecido. El ojo de la historia)

En su libro La experiencia opaca. Literatura y desencanto, Florencia Garramuño habla de "[u]na literatura que trabaja con restos de lo real", para referirse a "una lenta transformación del estatuto de lo literario que se ha venido manifestando en las prácticas de escritura desde los años setenta, y que en las culturas brasileña y argentina puede perseguirse, en senderos variados, a partir de algunas experimentaciones radicales que ocurrieron durante la década de $1970 \mathrm{y}$, con mayor ímpetu, en la de 1980" (Garramuño 15). Más precisamente, le interesa pensar "toda una miríada de prácticas artísticas que surcaron el paisaje cultural de las décadas de 1970 y 1980 en el Brasil y la Argentina y que establecieron una serie 
de relaciones problemáticas entre la noción de obra y su afuera o exterioridad" (18; énfasis de la autora). Y, al respecto, continúa:

La explosión de la subjetividad, la poesía marginal, el abandono del soporte obra [...], la proliferación de "formas híbridas" y de textos anfibios que se sostienen en el límite entre realidad y ficción son todos ejemplos de una fuerte impugnación a la categoría de obra de arte como forma autónoma y distanciada de lo real, suplantada por prácticas artísticas que se reconocen abiertas y permeadas por el exterior, y que resultan atravesadas por una fuerte preocupación por la relación entre arte y experiencia.

Textos que desestructuran géneros y subjetividades (todos los textos de Clarice Lispector publicados en los años sesenta y setenta, pero también los ilegibles textos de Osvaldo Lamborghini, poéticos y narrativos); narrativas que insisten en una primera persona aunque desestiman toda pulsión biográfica (El frasquito, de Luis Guzmán; La piel de caballo, de Ricardo Zelarayán; pero también todas las novelas de João Gilberto Noll), composiciones con apelaciones a eventos y ocurrencias contemporáneas a la escritura, plagadas de nombres de personas y de espacios reales (las novelas de Silviano Santiago, Nadie nada nunca y Glosa de Juan José Saer): todos esos textos que parecen existir como desgarramientos de formas o implosiones dentro del continente de una obra son ejemplos de estas transformaciones. Se trata de un tipo de escritura que, a pesar de hacer evidentes los restos de lo real que forman el material de sus exploraciones, se desprende violentamente de la pretensión de pintar una "realidad" completa regida por un principio de totalidad estructurante. (1819; énfasis de la autora) 
Los textos altamente "anfibios" de Diamela Eltit en torno a los cuales gira mi reflexión (El Padre Mío y El infarto del alma), así como las concomitancias entre esos textos y los de otros críticos descolocados que problematizan su propia práctica de lectura en la manifiesta afectación que provoca en ellos su arriesgar una respuesta a través de la escritura a la "catástrofe de lo Real" que no deja de interpelarlos, como diría Julio Ramos, podrían ser pensados en el marco de esa "transformación del estatuto de lo literario" señalada por Garramuño, y que bien podríamos reconocer en otros ámbitos culturales de América Latina -como el chileno, por ejemplo. No obstante, más allá de lo que traduce tal acogida de los restos de lo Real acerca de esa "transformación", me interesa destacar lo que señala también a propósito de la emergencia de otro tipo de posición autoral que, lejos de resguardarse en el interior autónomo de su discurso, se expone hacia el afuera problemático que excede a lo simbólico; así como de otra manera de asumir la escritura crítica desde esa posición descolocada. Una posición que se funda en el reconocimiento de una deuda con eso Real que, en su radical exterioridad, no deja de reclamar una posibilidad de hacerse manifiesto entre nosotros, así sea como desarreglo, mancha, temblor o ruido.

En el "caso" de la escritura de Eltit que nos ocupa, la autora recurre a la literatura y al arte; toda vez que, en tanto espacios de implicación subjetiva y trabajo significante, ellos le permiten desplazarse hacia la factura más bien experimental de un texto capaz de instalar entre nosotros los efectos devastadores del exterior ineludible que, como decía al principio, hace causa en su deseo de escritura... A fin de cuentas, como bien ha señalado Deleuze en su libro Crítica y clínica, si bien lo Real es aquello que no encuentra lugar en lo simbólico, no dejan de ser la literatura y el arte los únicos espacios capaces de ofrecer albergue a sus restos. Y, en efecto, como señala Julio Ramos, siguiendo de cerca la reflexión de este filósofo afecto al comentario de textos literarios y artísticos:

En los momentos más radicales de sus recorridos, la literatura, como la demencia, también atravesará los límites, sometiendo el orden de las 
articulaciones, de la lengua misma, a la tensión más plena de la errancia y el extravío. Porque, ¿no supone la escritura el riesgo irreductible de la pérdida del sentido, allí donde la materialidad proliferante del cuerpo y la particularidad parecieran cancelar el dominio, la efectividad de las categorías del pensamiento? Allí, en el espacio plano donde se disuelven las diferencias más básicas y sus economías de sentido, la literatura intentará cancelar las categorías de su identidad y de su nombre. Allí, sin embargo, postulará, con el gesto mismo de la cancelación del nombre, una ética, un juicio a veces severo, un albergue para el extravío, para los escombros, los restos que deja en su paso la lógica del buen sentido y la racionalidad. Volverá de allí iluminada, a poner en forma, a dar cuenta de la catástrofe que ha visto. (Ramos 220)

"Pensar la política, la catástrofe de lo real, desde la estética”, y a partir de una posición subjetiva que "no soslaya la problemática de su responsabilidad, de su inserción en el circuito de las interpretaciones sociales”, según Julio Ramos (225), sería uno de los ejes estructuradores de las búsquedas escriturales de Eltit. $Y$, en este sentido, considero que los textos marginales que acompañan enigmáticos y contundentes a su productividad teórico-ficcional, esos textos que insisto en traer al presente de una lectura al pie de la letra en este trabajo, constituyen una entrada posible para ver lo que entre ellos se presenta como las "formas profanas" (Agamben 95 y ss.) de/por una autoría excéntrica de la crítica cultural en América Latina. 


\section{Bibliografía}

Agamben, Giorgio. Profanaciones. Barcelona: Anagrama, 2005.

Barthes, Roland. Barthes por Barthes. Caracas: Monte Évila Editores, 1992.

Didi-Huberman, Georges. Arde la imagen. Oaxaca: Ediciones Ve / Fundación

Televisa, 2012.

Deleuze, Gilles. Crítica y clínica. Barcelona: Anagrama, 1996.

Eltit, Diamela. El Padre Mío. Santiago de Chile: Francisco Zegers Editor, 1989.

Eltit, Diamela y Paz Errázuriz. El infarto del alma. Santiago de Chile: Francisco Zegers Editor, 1994.

Garramuño, Florencia. La experiencia opaca. Literatura y desencanto. Buenos

Aires: Fondo de Cultura Económica de Argentina, 2009.

Lacan, Jacques. “Lituratierra”. En: Otros escritos. Buenos Aires: Paidós, 2012.

Lispector, Clarice. A Paixão segundo G.H. Florianópolis: Editora da UFSC, Colecção Arquivos, 1988.

. "La bella y la bestia o la herida demasiado grande". Cuentos reunidos.

Madrid: Alfaguara, 2002.

Ramos, Julio. "Dispositivos del amor y la locura". Estudios. Revista de

Investigaciones Literarias y Culturales 11 (1998): 219-226.

Richard, Nelly. La insubordinación de los signos (cambio político, transformaciones culturales, poéticas de la crisis). Santiago de Chile: Cuarto Propio, 1994.

Richard, Nelly. "En torno a las ciencias sociales: saberes regladores y poéticas de la crisis". Fracturas de la memoria. Arte y pensamiento crítico. Buenos Aires: Siglo XXI Editores Argentina, S.A., 2007. 